NASA/TM—2008-215278

\title{
Scalability of Localized Arc Filament Plasma Actuators
}

Clifford A. Brown

Glenn Research Center, Cleveland, Ohio 


\section{NASA STI Program . . . in Profile}

Since its founding, NASA has been dedicated to the advancement of aeronautics and space science. The NASA Scientific and Technical Information (STI) program plays a key part in helping NASA maintain this important role.

The NASA STI Program operates under the auspices of the Agency Chief Information Officer. It collects, organizes, provides for archiving, and disseminates NASA's STI. The NASA STI program provides access to the NASA Aeronautics and Space Database and its public interface, the NASA Technical Reports Server, thus providing one of the largest collections of aeronautical and space science STI in the world. Results are published in both non-NASA channels and by NASA in the NASA STI Report Series, which includes the following report types:

- TECHNICAL PUBLICATION. Reports of completed research or a major significant phase of research that present the results of NASA programs and include extensive data or theoretical analysis. Includes compilations of significant scientific and technical data and information deemed to be of continuing reference value. NASA counterpart of peer-reviewed formal professional papers but has less stringent limitations on manuscript length and extent of graphic presentations.

- TECHNICAL MEMORANDUM. Scientific and technical findings that are preliminary or of specialized interest, e.g., quick release reports, working papers, and bibliographies that contain minimal annotation. Does not contain extensive analysis.

- CONTRACTOR REPORT. Scientific and technical findings by NASA-sponsored contractors and grantees.

- CONFERENCE PUBLICATION. Collected papers from scientific and technical conferences, symposia, seminars, or other meetings sponsored or cosponsored by NASA.

- SPECIAL PUBLICATION. Scientific, technical, or historical information from NASA programs, projects, and missions, often concerned with subjects having substantial public interest.

- TECHNICAL TRANSLATION. Englishlanguage translations of foreign scientific and technical material pertinent to NASA's mission.

Specialized services also include creating custom thesauri, building customized databases, organizing and publishing research results.

For more information about the NASA STI program, see the following:

- Access the NASA STI program home page at http://www.sti.nasa.gov

- E-mail your question via the Internet to help@ sti.nasa.gov

- Fax your question to the NASA STI Help Desk at 301-621-0134

- Telephone the NASA STI Help Desk at 301-621-0390

- Write to: NASA Center for AeroSpace Information (CASI) 7115 Standard Drive Hanover, MD 21076-1320 
NASA/TM-2008-215278

\section{Scalability of Localized Arc Filament Plasma Actuators}

\section{Clifford A. Brown}

Glenn Research Center, Cleveland, Ohio

Prepared for the

14th Aeroacoustics Conference

sponsored by AIAA and CEAS

Vancouver, British Columbia, Canada May 5-7, 2008

National Aeronautics and

Space Administration

Glenn Research Center

Cleveland, Ohio 44135 
This work was sponsored by the Fundamental Aeronautics Program at the NASA Glenn Research Center.

Level of Review: This material has been technically reviewed by technical management.

Available from

NASA Center for Aerospace Information

7115 Standard Drive

Hanover, MD 21076-1320
National Technical Information Service 5285 Port Royal Road Springfield, VA 22161

Available electronically at http://gltrs.grc.nasa.gov 


\title{
Scalability of Localized Arc Filament Plasma Actuators
}

\author{
Clifford A. Brown \\ National Aeronautics and Space Administration \\ Glenn Research Center \\ Cleveland, Ohio 44135
}

\begin{abstract}
Temporal flow control of a jet has been widely studied in the past to enhance jet mixing or reduce jet noise. Most of this research, however, has been done using small diameter low Reynolds number jets that often have little resemblance to the much larger jets common in real world applications because the flow actuators available lacked either the power or bandwidth to sufficiently impact these larger higher energy jets. The Localized Arc Filament Plasma Actuators (LAFPA), developed at the Ohio State University (OSU), have demonstrated the ability to impact a small high speed jet in experiments conducted at OSU and the power to perturb a larger high Reynolds number jet in experiments conducted at the NASA Glenn Research Center (GRC). However, the response measured in the large-scale experiments was significantly reduced for the same number of actuators compared to the jet response found in the small-scale experiments. A computational study has been initiated to simulate the LAFPA system with additional actuators on a large-scale jet to determine the number of actuators required to achieve the same desired response for a given jet diameter. Central to this computational study is a model for the LAFPA that both accurately represents the physics of the actuator and can be implemented into a computational fluid dynamics solver. One possible model, based on pressure waves created by the rapid localized heating that occurs at the actuator, is investigated using simplified axisymmetric simulations. The results of these simulations will be used to determine the validity of the model before more realistic and time consuming three-dimensional simulations are conducted to ultimately determine the scalability of the LAFPA system.
\end{abstract}

\section{Introduction}

The idea of temporal flow control for jet noise reduction is not new. In fact, considerable research has been dedicated to this concept since the 1950s and the advent of the commercial jet aircraft. The flow control actuator technology available, however, has limited this research to small-scale low Reynolds number jets that often have little resemblance to the much larger high Reynolds number jets common in real world applications. This resulted in a stagnation of research for active control for noise reduction as even a successful noise reduction concept could not advance far beyond the laboratory scale. Actuator research, however, has continued with the hope of finding an actuator technology with the power and frequency response to exert control on larger jets. Some of these actuators influence the flow by moving a physical barrier into and out of the flow to create a high amplitude force but with a relatively low frequency response (ref. 1). Other actuator concepts, such the synthetic jet (ref. 2) or the flip-flop jet (ref. 3); use momentum transfer from air added periodically to influence the jet. Again, however, these fluidic actuators lack either the amplitude or frequency response to excite large-scale, high Reynolds number jets. In both cases, the actuator technology has not allowed research of jet excitation for noise reduction to advance far beyond small-scale, low Reynolds number jets. A new actuator based on high voltage high frequency electronics, however, may finally overcome some of the limitations of jet actuators.

The Localized Arc Filament Plasma Actuators (LAFPA) have been developed at the Ohio State University (OSU) as a high frequency, high amplitude device suitable for use on high speed, 
high Reynolds number jets (ref. 4) Flow data acquired has shown that the LAFPA have the ability to excite a small (jet diameter $\mathrm{D}_{\mathrm{j}}=1.0 \mathrm{in}$.), high-speed, turbulent jet (Reynolds number based on jet diameter, $\operatorname{Re}_{\mathrm{D}} \approx 1.1 \times 10^{6}$ ) (ref. 5), affecting jet instabilities over a range of frequencies and at several azimuthal modes, a requirement for actuators seeking noise reduction through active control. Acoustic data acquired showed the LAFPA also impact the noise created by the smallscale jet (ref. 6).

Historically, jet excitation has been shown to impact jet noise. Yet, especially in the case of noise reduction, the results have not been confirmed on the large diameter and high Reynolds number jets more typical in real world applications, in part because the jet actuators available did not have sufficient power to impact the larger jets. The LAFPA, however, showed enough promise for exciting a small-scale jet that a test using the actuators on the large-scale High Flow Jet Exit Rig (HFJER) at the NASA GRC were conducted to study the flow and acoustic effect of the actuators on a large subsonic jet $\left(D_{j}=7.55\right.$ in., fig. 1) (ref. 7). Unfortunately, the results of these tests were inconclusive. While the actuators definitely had an impact on the jet, the jet's response did not reach the same amplitude observed during the smaller scale experiments. While unsteady pressure measurements recorded for the $\mathrm{D}_{\mathrm{j}}=1.0 \mathrm{in}$. jet $\left(\mathrm{Re}_{\mathrm{D}}=7.2 \times 10^{5}\right)$ showed an increase of more than $30 \mathrm{~dB}$ compared to the baseline jet at the excitation frequency, the $\mathrm{D}_{\mathrm{j}}=$ 7.55 in. jet $\left(\operatorname{Re}_{\mathrm{D}}=5.5 \times 10^{6}\right)$ only responded with an increase of approximately $3 \mathrm{~dB}$ over the baseline jet (fig. 2). It is important to note that only eight actuators could be simultaneously activated in both the small-scale and large-scale experiments (because of the limited LAFPA hardware available) so the reduced response of the large-scale jet was not entirely unexpected. The response was sufficient that, even with the limited number of actuators, further testing with the LAFPA system on a large-scale jet is warranted but additional work is required to determine the proper number of actuators required to replicate the small-scale results.

The LAFPA system showed promise by successfully perturbing a large-scale jet but it did not generate the same amplitude response measured on a small-scale jet using the same number of actuators. Therefore, a study was initiated to determine the scalability, or number of actuators required to get a similar amplitude response from a larger jet to one measured on a smaller jet, of the actuator system before future tests investigate the potential noise reduction on a large-scale jet. But, because of the specialized hardware and expense of adding additional actuators to the system, further experiments were not practical. Computation fluid dynamics (CFD) would be

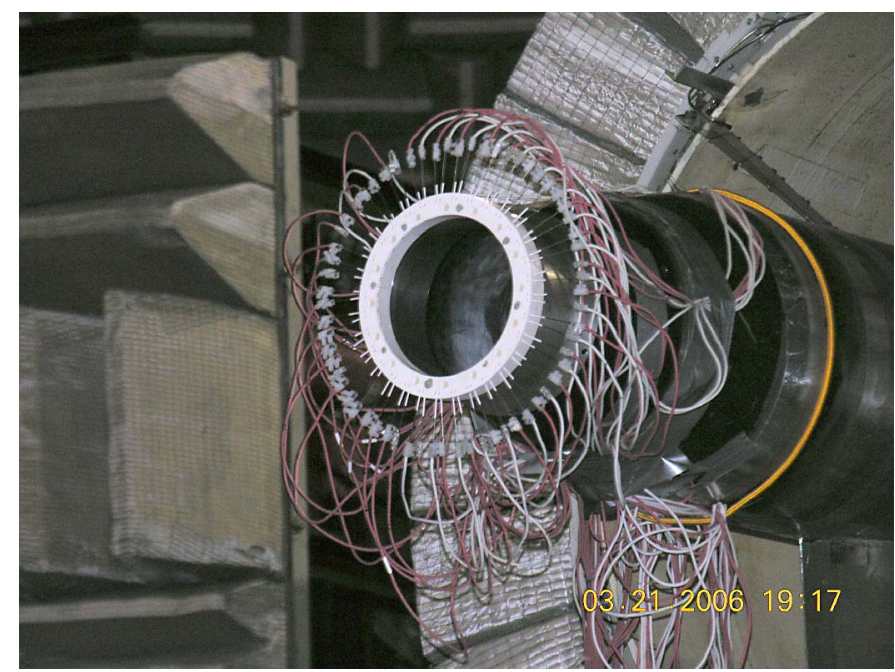

Figure 1.-The plasma actuators installed on the HFJER at the GRC. The jet diameter $\left(D_{j}\right)$ is 7.55 in. 


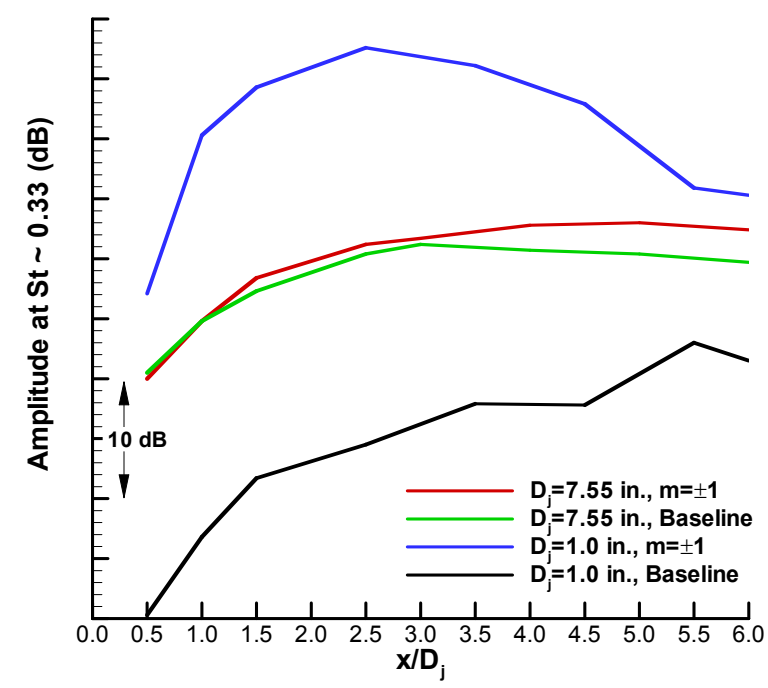

Figure 2.-Axial growth of perturbations, input at azimuthal mode $m= \pm 1$ at Strouhal number based on jet diameter $S t_{D} \approx 0.33$, from the $D_{j}=7.55$ in. jet tested at NASA GRC and the $D_{j}=1.0$ in. jet tested at OSU (ref. 6). Both jets were operating at acoustic Mach number $\left(M_{a}=v_{j} / c_{a}\right) 0.84$ and no heat was added.

used to simulate jets of different diameters with varying numbers of plasma actuators. Central to this work was a model of the plasma actuators that could be implemented in the CFD solver and allow changes in actuator number and power. One LAFPA model, using temperature and pressure as the working variables, is proposed and examined here.

\section{CFD Modeling}

\section{LAFPA Model}

One challenge using CFD to simulate the jet excitation experiments conducted at OSU and NASA is creating an accurate model of the plasma actuators to achieve the correct impact on the jet within the confines of an existing CFD code. Fortunately, a review of recent literature gives significant insight to the forces that may be at work in a plasma system. In the case of the LAFPA, there are three forcing mechanisms that must be considered when dealing with fluids in the plasma regime. The first two are related and arise from the charged nature of the plasma particles: the electohydrodynamic (EHD) and magnetohydrodynamic (MHD) forces. While the EHD interaction may play a significant role in boundary layer flow control by surface glow discharge plasma, the EHD forces are limited in high-speed flow control by the high levels of ion density that must be maintained to generate the force (ref. 8). Therefore, the EHD interactions may be neglected in the current model for excitation of high-speed jets. Similarly, the MHD forces in a high-speed flow would only be significant in very a low pressure environment where higher flow conductivities can be maintained (ref. 8). Like the EHD forces, the MHD interactions may be neglected in high-speed jets operating at atmospheric pressure.

The third possible force generated by plasma based flow control is Joule heating. The LAFPA system heats the flow in short repetitive bursts that generate shock waves in the flow. Schlieren images have shown that these shock waves, generated near a surface by an arc plasma system, can influence flow separation (ref. 9) and could behave similar to solid surfaces in supersonic flows (ref. 10). Repetitive firing of a series of plasma actuators could act like very high frequency mechanical actuators where small tabs are rapidly inserted and removed from the flow in patterns 
and frequencies that target specific jet instabilities. The Joule heating thermal effect appears to be the driving force behind the LAFPA system in the high Reynolds number jets of practical interest.

Analysis of the possible forces at work in the plasma actuator system indicates that pressure waves, generated by rapid localized heating, are the mechanism actually impacting the jet. Therefore, a model of the LAFPA system must simulate this rapid heating, and the pressure waves generated, at the proper locations near the nozzle exit. There are three primary issues that must be considered. First, the heating occurs over a very short time. Second, the amount of heat generated by the plasma and the strength of the pressure wave generated is not precisely known. Finally, the model must be implemented within the confines of a CFD solver. Figure 3 shows a plot of input signal, voltage, current, and power as a function of time for the plasma actuators. The square wave input signal results in near instantaneous rise in voltage, current, and power response. And while the power trace in figure 3 shows the electrical power used by one actuator, this is not a convenient value to input into the CFD solver because electrical power does not easily relate to the flow parameters. Emission spectroscopy measurements, conducted at OSU, can give further insight into both of these parameters (ref. 8). The OSU team found that the plasma temperature increased from below $1000{ }^{\circ} \mathrm{C}$ to approximately $2000{ }^{\circ} \mathrm{C}$ during the first 10 to $20 \mu$ s of operation. The temperature then stabilizes after this initial increase for pulse durations up to $100 \mu \mathrm{s}$. These measurements help to put the operation of the plasma actuators into terms more usable by the CFD codes but the exact relationship between the plasma temperature and the strength of the pressure wave generated is still not know. Also, implementation of the model into the CFD solver remains another challenge.

There are several of ways the LAFPA system could be modeled in the CFD solver. One possibility considered was to put a temperature wall boundary at the actuator location and let the CFD code solve for the heat transfer and increase in flow temperature. While this could put the desired heat into the flow, it would take much longer than the heating time determined by the emission spectroscopy and may then have problems generating the pressure waves that impact the flow. Therefore, a second model was developed that takes advantage of the geometry of the
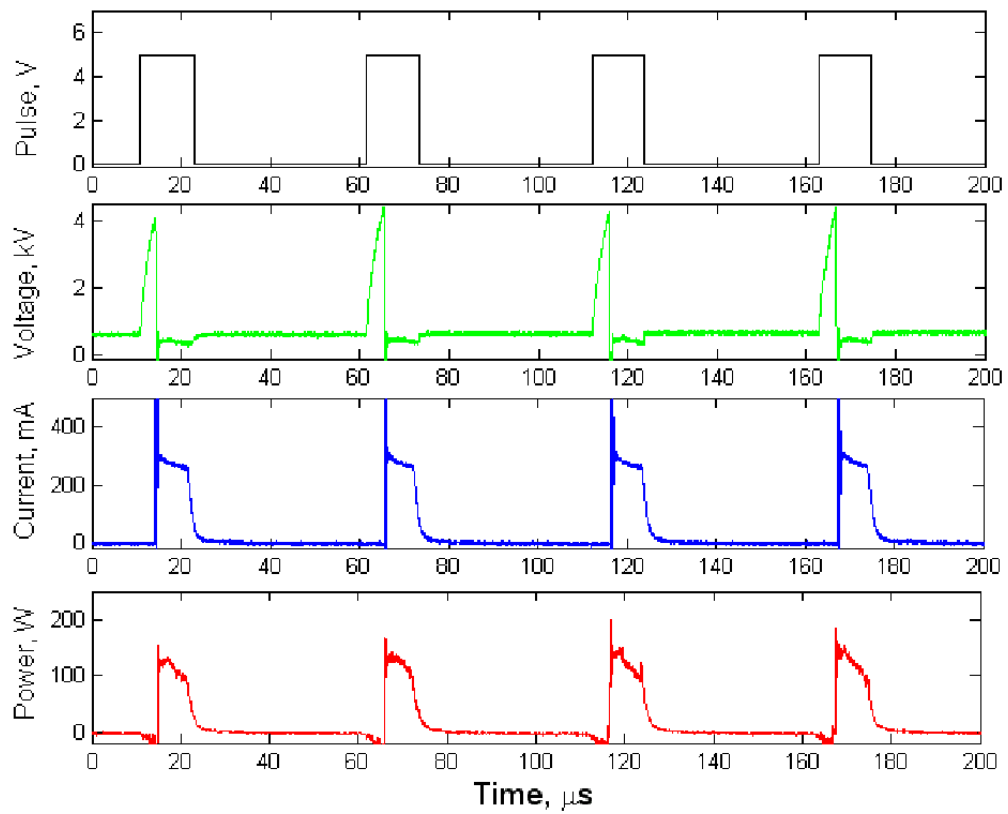

Figure 3.-From top to bottom, time traces of the plasma actuator input signal, voltage, current, and power. Note the square wave input signal and the near instantaneous rise in voltage, current, and power that needs to be reflected in the plasma actuator model (ref. 7). 
nozzle extension in the implementation. The Boron Nitride ceramic nozzle extension used in both the OSU and NASA experiments has a groove 0.039 in. $(1 \mathrm{~mm})$ upstream of the nozzle exit to hold the plasma electrodes just outside of the flow (OSU researchers found that the flow will blow the spark off the electrodes without the groove). This groove is $0.059 \mathrm{in}$. $(1.5 \mathrm{~mm})$ wide (axial direction) and $0.051(1.3 \mathrm{~mm})$ deep (radial direction). The electrodes are separated by 0.118 in. $(3 \mathrm{~mm})$. The actuator model could use this entire volume, defined as a separate block in the grid, to act as the actuator. To activate the actuator, the CFD code is stopped and the temperature and pressure values stored in this block of cells are reset to the higher values that reflect the energy input by the actuator. These values are initially based on the temperature determined by the emission spectroscopy measurements, but could be easily adjusted later to match the flow data. A corresponding pressure is calculated using the plasma temperature and the ideal gas law. It is a significant assumption to use the ideal gas law here as plasma is not an ideal gas but it does give some representative value that allows the actuator model to be calibrated later by a comparison to flow data. There is, however, a possibly significant limitation inherent in this model: the actuators employed in the experiment did not turn instantly on and off. Rather the actuators came on over a very short duration $(\sim 20 \mu \mathrm{s})$ and remained on for some specified time (defined by the duty cycle in the control system) allowing additional heat transfer to the flow. The proposed model does not capture this feature but relies on the pressure wave generated during the initial breakdown of the air to be the dominant force acting on the flow. A series of axisymmetric simulations will be used to test these assumptions before the more complex and time consuming three-dimensional simulations are run.

\section{Computational Strategy}

The LAFPA have demonstrated an ability to excite a small-scale $\left(D_{j}=1.0\right.$ in. $)$ high-speed jet for enhanced jet mixing and noise reduction. These actuators have also shown an ability to influence a larger diameter $\left(D_{j}=7.55 \mathrm{in}\right.$.) high-speed jet but with a significantly reduced jet response than observed in the small-scale tests. However, these experiments held constant the number of actuators activated at any time leaving the possibility that a similar jet response could be achieved at all scales with an appropriate increase in the number of actuators. To test this theory experimentally would require a significant investment in many more plasma actuators and expensive nozzle hardware, but it could be investigated using CFD to simulate a wide range of nozzle sizes, jet velocities, and number of actuators.

The Wind-US version 1.0 CFD solver was used to simulate both the baseline (actuators disabled) and LAFPA perturbed jets. The Wind-US code was developed and is currently maintained by the NPARC Alliance, a partnership between the GRC and the UASF Arnold Engineering Development Center (refs. 11 to 13). Wind-US is a multi-purpose three-dimensional solver for both the Euler and Reynolds Averaged Navier-Stokes (RANS) equations, in both steady state and unsteady modes, with support modules for turbulent and chemically reacting flows. Although there are several turbulence models available in Wind-US that are applicable for these simulations, it has been shown that the Menter SST turbulence model (ref. 14) is the best choice for jet flows (refs. 15 and 16). A second-order Roe upwind scheme modified for stretched grids and using a TVD flux limiter was used for all simulations. Wind-US includes a MacCormack DQ limiter (ref. 17) and a TVD flux limiter. The MacCormack DQ limiter prevents the density and temperature from to only fractional changes (default is \pm 50 percent) over a single iteration. Because of the large instantaneous changes placed in the flow by the actuator model, results from the early test runs showed improvement compared to the experimental data when the DQ limiter was not used and, therefore, the DQ limiter was disabled in all future runs. Minimal changes to the excited mode growth and decay were observed when the TVD limiter was disabled so it was used for future runs in an effort to improve code stability. 
Wind-US is capable of using both structured and unstructured multi-block grids though all grids used for this research were structured. A two-dimensional axisymmetric grid of the $\mathrm{D}_{\mathrm{j}}=$ 1.0 in. nozzle tested at OSU is shown in figure 4. Grid points were clustered around the actuator where the steepest gradients were expected. Grid points were also clustered to the internal nozzle boundary, thick nozzle lip (both treated as viscous walls), and centerline axis of symmetry. The external nozzle surface was simplified and treated as an inviscid wall to avoid the additional grid complexity and computational expense that would have been required to recreate the actual profile after preliminary tests showed that this surface had little impact due to the unusually thick nozzle lip required by the plasma system. The top boundary was placed 20 jet diameters from the nozzle centerline and was also treated as an inviscid wall to avoid any problems that may arise from a freestream inflow boundary in a region of very little flow. The outflow boundary was placed 40 jet diameters downstream of the nozzle exit. The Wind-US code supports the use of grid sequencing which was used to speed up convergence of the baseline solutions. The baseline solutions also were computed using a constant time step rather than a constant CFL number which may have speeded convergence because it was found that some numerical perturbations formed when switching from constant a CFL number to a constant time step requiring additional run time to reconverge and negating any time gained from using a constant CFL number in the baseline solution. Convergence for the baseline case, where the actuators were disabled, was determined when the change in maximum change centerline velocity profile was below 0.05 percent for two consecutive runs (approximately 30,000 iterations).

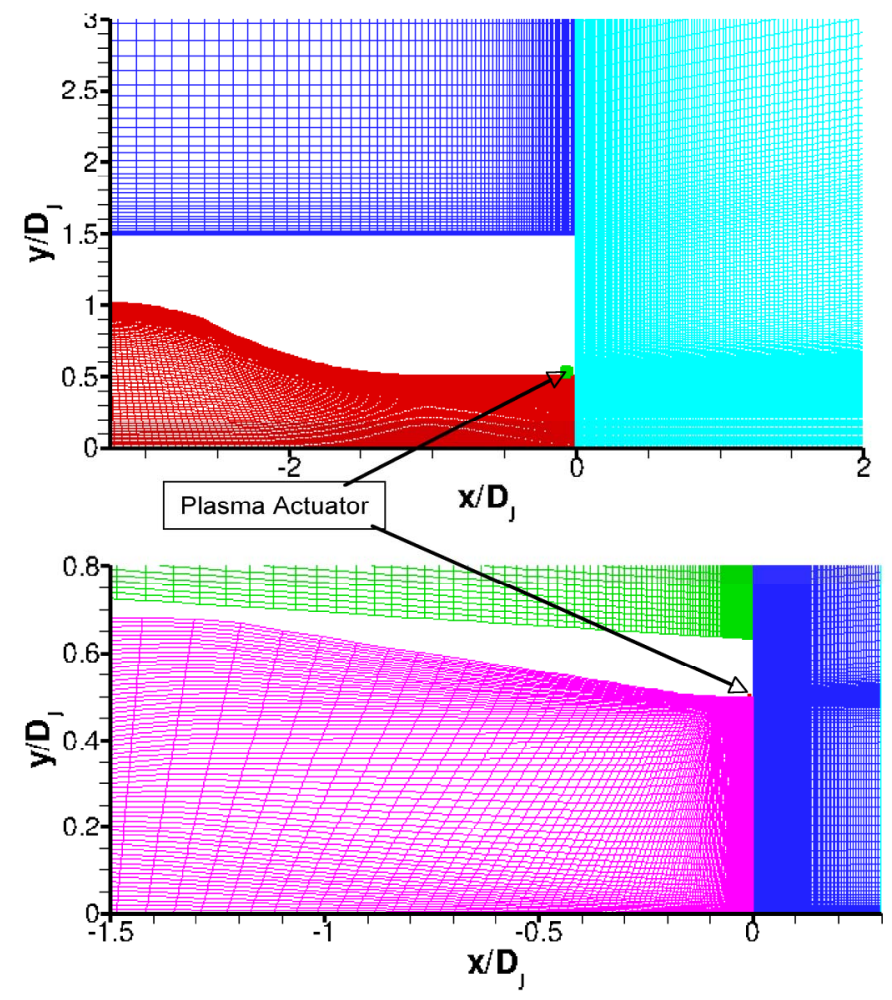

Figure 4.-The two-dimensional axisymmetric grids for the $D_{j}=1.0$ in. nozzle tested at OSU (top) and the $D_{j}=7.55$ in. nozzle tested at NASA (bottom). An enlarged view of the nozzle is shown with the LAFPA actuator. The plasma actuator is $0.059 \mathrm{in}$. $(1.5 \mathrm{~mm})$ deep (radial direction) and $0.059 \mathrm{in}$. (1.5 mm) wide (axial direction). It is located $0.039 \mathrm{in}$. $(1 \mathrm{~mm})$ from the nozzle exit. Note the unusually thick nozzle lip that is required by the plasma system and the simplified external nozzle surface in both nozzles. 
The actuators were implemented in the grid as a small block of cells near the nozzle exit (fig. 4). The dimensions of the volume were set to match the actuator groove in the actual nozzle and, in the three-dimensional grids, the arc length of the volume would match the separation between the actuator electrodes. The actuator walls were treated as inviscid surfaces. Experience showed a time step of $100 \mathrm{~ns}$ to be the largest possible without compromising the stability of the solution when the plasma actuator is activated. All simulations targeted a particular Strouhal number so that the time between plasma pulses varied depending on the jet diameter and exit velocity. The number of iterations per actuator cycle could be found from the time step and desired frequency. Starting with the baseline solution, the temperature and pressure of the cells in the actuator volume were reset to the plasma values. Wind-US was then run for a number of iterations corresponding to the desired actuator frequency $(\mathrm{N}=1 /(\mathrm{f} \times \mathrm{t}))$. When complete, WindUS would exit, the plasma cells reset and another cycle run. Each simulation was run for no less than eight complete cycles.

The complete flow field was sampled at a rate of $50 \mathrm{kHz}$ (every $10 \mu \mathrm{s}$ ) during each run. The pressure data from several points in the flow field was then extracted from each flow field to get a time history of the pressure similar to the in-flow pressure transducer data measured during the experiments at NASA and OSU. Analysis of the CFD pressure data showed that it took four complete cycles at an axial location before the solution became periodic (based on the response amplitude at the excitation frequency). One period was then selected, repeated several times to create a longer time record (to get the desired frequency bandwidth), and a Fourier transform computed to determine the response amplitude at the excitation frequency which is a tone in the pressure spectrum. When repeated at several axial locations, this process gives the axial growth and decay of the jet response at the excitation frequency, a metric commonly used to characterize the actuators in experiments.

\section{Axisymmetric Flow Results}

A model for the plasma actuator was proposed based on prior research into the forces at work inside plasma and how each force might work in a high-speed jet. Axisymmetric two-dimensional simulations were conducted to gain some insight into the physics of the model and to get some experience with grid and time step requirements for stability of the Wind-US solver with the sudden high amplitude changes imposed by the actuators. The axisymmetric approximation is actually the limiting case in which the actuator is treated as one continuous spark around the complete circumference of the nozzle. Unlike the many independent actuators present in the experiments and three-dimensional simulations, it is only possible to excite the axisymmetric mode $(\mathrm{m}=0)$ in the axisymmetric simulations.

Both the small-scale nozzle, tested at OSU, and the large-scale nozzle, tested at NASA, were simulated with the plasma actuator model. Contours of mean axial velocity with the actuators disabled (baseline) from the OSU $\left(\mathrm{D}_{\mathrm{j}}=1.0\right.$ in.) and NASA $\left(\mathrm{D}_{\mathrm{j}}=7.55 \mathrm{in}\right.$.) nozzles are shown in figure 5. Mean axial velocity profiles after several actuator cycles, operating at a Strouhal forcing frequency based on jet diameter $\left(\mathrm{St}_{\mathrm{DF}}\right)$ of $\mathrm{St}_{\mathrm{DF}}=0.3$,are shown in figure 6. Although the actuator power was based on a plasma temperature of $1000^{\circ} \mathrm{C}$, which is only about half the peak temperature measured at OSU, the pressure waves appear to easily penetrate to the jet centerline effectively choking the jet periodically and creating regions of lower velocity flow in both the small-scale and large-scale jets. It is important to remember that the actuators in the axisymmetric simulation circle the entire jet and, therefore, should have more power than in the actual experiments. Nevertheless, this limiting case demonstrates the potential power this type of actuator could possess if deployed in high enough numbers. 

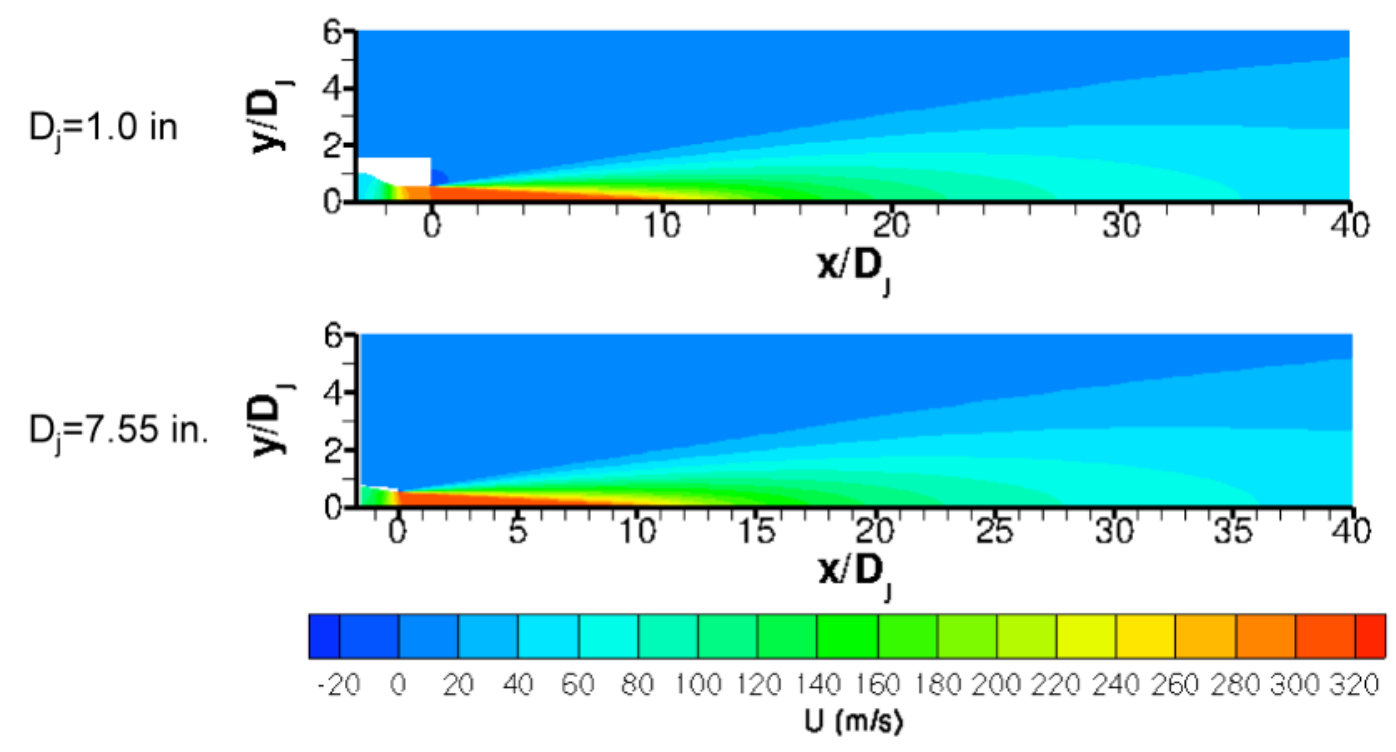

Figure 5.-Average axial velocity profiles for the two-dimensional axisymmetric baseline OSU

$\left(D_{j}=1.0\right.$ in. $)$ and NASA $\left(D_{j}=7.55\right.$ in.) nozzles operating at a $M_{a}=0.9$, cold jet exit condition.
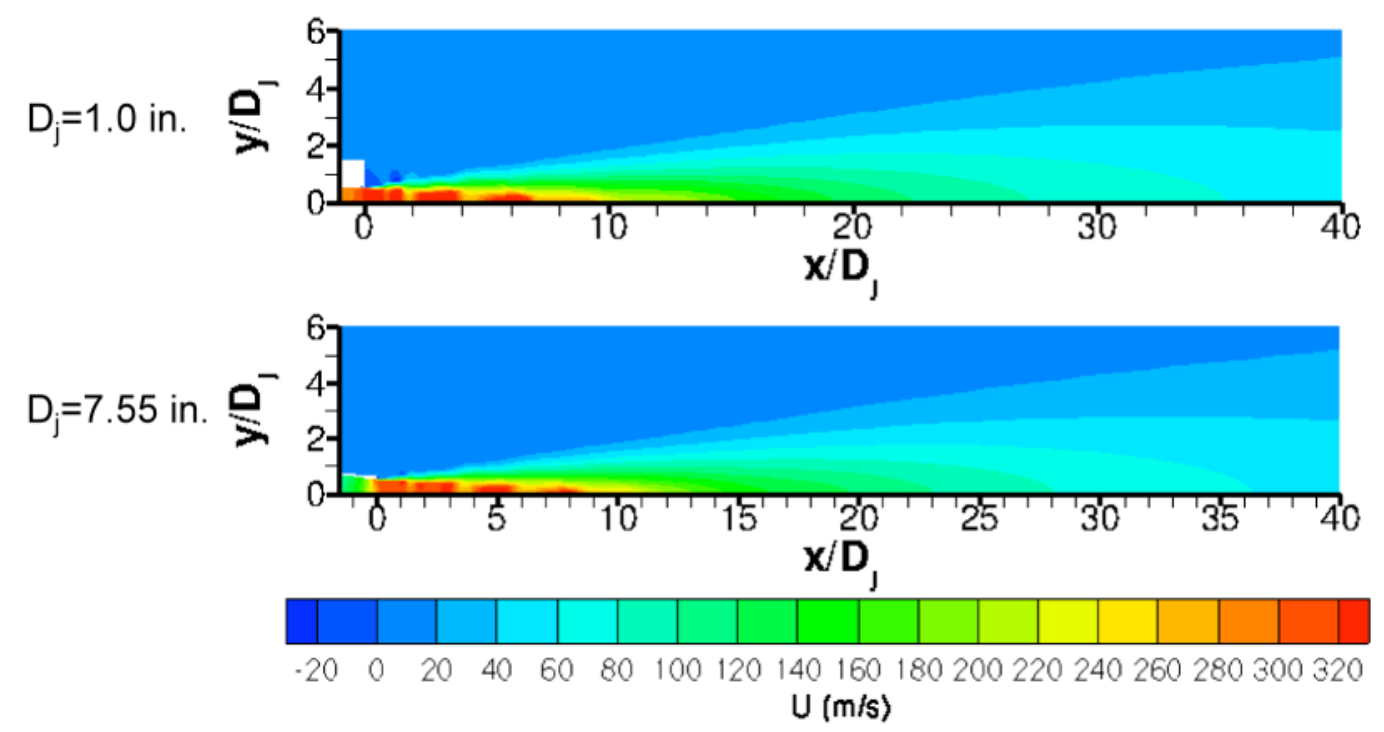

Figure 6.-Average axial velocity profiles for the two-dimensional axisymmetric OSU $\left(D_{j}=1.0\right)$ and NASA $\left(D_{j}=7.55\right.$ in. $)$ jets with the plasma actuators active. The actuator forcing frequency is $S t_{D F}=0.3$ and the actuator power is set using a plasma temperature of $1000^{\circ} \mathrm{C}$.

Results of the CFD simulations of the plasma actuators showed clearly that the actuators had a significant impact on the flow. It is another question, however, whether the modeled actuators create a response in the jet similar to the actuators used in the experiments. Figure 7 shows the axial growth and decay of the pressure fluctuations along the nozzle lipline $\left(y / D_{j}=0.5\right)$ at the excitation frequency as measured in an acoustic Mach number $0.84\left(\mathrm{M}_{\mathrm{a}}=\mathrm{v}_{\mathrm{j}} / \mathrm{c}_{\mathrm{a}}\right.$, where $\mathrm{v}_{\mathrm{j}}$ is the jet velocity and $\mathrm{c}_{\mathrm{a}}$ is the ambient speed of sound) jet using 8 discrete actuators at OSU (all fired simultaneously) and the continuous actuator modeled in the axisymmetric CFD simulations (assuming a plasma temperature of $100{ }^{\circ} \mathrm{C}$ ). Given the differences in the actuator systems, the results are encouraging. The initial growth rate, an important characteristic of the jet response, is 


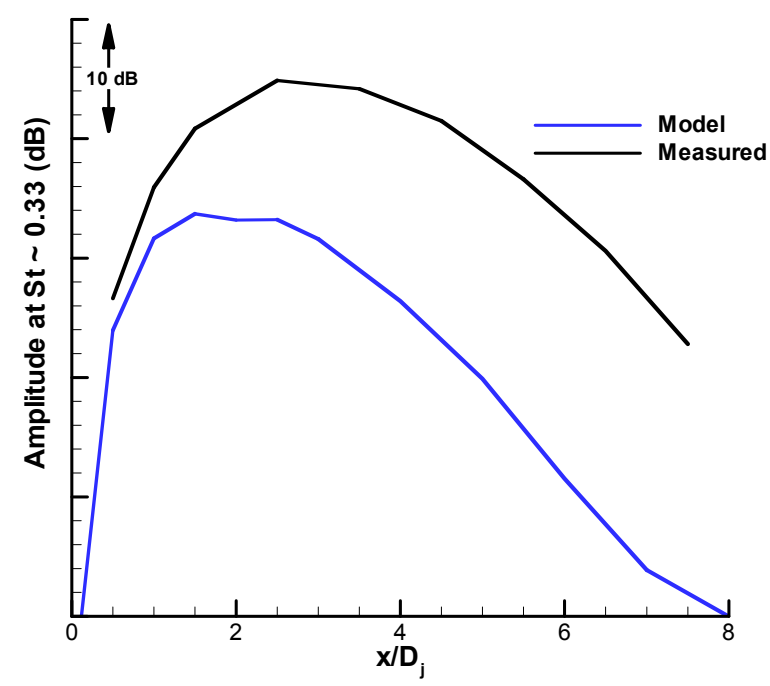

Figure 7.-Axial growth of the excited axisymmetric mode, $\mathrm{m}=0$, at the excitation frequency $\left(\mathrm{St}_{\mathrm{DF}}=\right.$ 0.3 ) from a $\mathrm{M}_{\mathrm{a}}=0.84$, cold jet measured at OSU (ref. 6) and determined using the two-dimensional CFD actuator simulation.

similar over the first $\mathrm{x} / \mathrm{D}_{\mathrm{j}}=0.5$ although the experiments showed the response at a slightly higher amplitude (approximately $1 \mathrm{~dB}$ ). The growth rate remains similar over the next $\mathrm{x} / \mathrm{D}_{\mathrm{j}}=0.5$, out to $\mathrm{x} / \mathrm{D}_{\mathrm{j}}=1.0$ downstream of the nozzle exit, but the jet response to the model is starting to lessen compared to the measured response. Around $\mathrm{x} / \mathrm{D}_{\mathrm{j}}=1.5$ the jet response to the model actuators saturates and remains at a consistent level until around $x / D_{j}=3$. The jet response measured at OSU, however, continues to grow and has a more defined peak around $x / D_{j}=3$. Both the measured response and the response determined by the CFD simulation decay at similar rates after $\mathrm{x} / \mathrm{D}_{\mathrm{j}}=3$, though the measured data shows a consistently higher amplitude compared to the CFD data as it is originating at a considerably higher peak level. Overall, this result is encouraging given the considerable assumptions (e.g., the continuous axisymmetric actuator and plasma follows the ideal gas law) that went into the plasma actuator model at this point and that the power (temperature and pressure) of the model actuator has not been adjusted to get a jet response amplitude that matches the data (this will be done with discrete actuators in a future three-dimensional simulation). Also, some reduction in jet response in the CFD could be expected because of the added dissipation present in an unsteady RANS type solver, a factor that may contribute to the reduced jet response at the saturation point. For the scalability study, the initial perturbation level and the initial growth rate are probably the most important aspects to capture because once the excitation is started the exact mode saturation levels will be determined by the individual jet. Unfortunately, no data targeting the axisymmetric mode was acquired using the larger NASA nozzle so the OSU data is the only data available for comparing to the twodimensional axisymmetric model.

A LAFPA model has been developed and preliminary results, based on limited comparisons to measured data, were encouraging. The peak amplitude of the jet response, however, was lower for the CFD model than the experimental data. One feature of the actuator model is the ability to easily change the actuator power by specifying a different temperature and corresponding pressure (in the CFD actuator model temperature is used a means to specify a pressure via the ideal gas law) which is not possible in the experimental actuators. Therefore, several simulations were run to study how adjustments to the actuator parameters would change the response of the jet. Figure 8 shows the axial mode growth for the $D_{j}=7.55$ in. jet with a $M_{a}=0.9$ jet exit velocity 


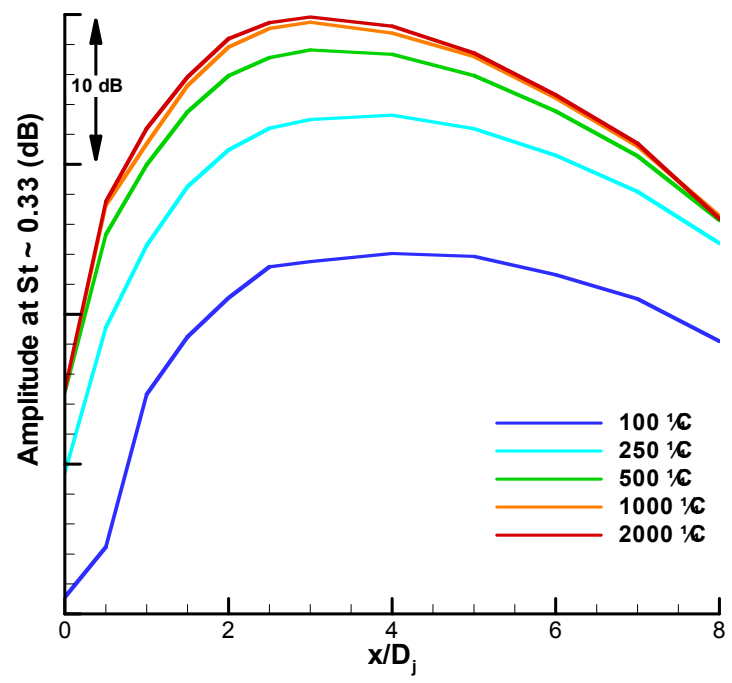

Figure 8.-Axial growth of the excited axisymmetric mode, $m=0$, at the excitation frequency $\left(\mathrm{St}_{\mathrm{DF}}=\right.$ 0.3 ) from $a D_{j}=7.55$ in., $M_{a}=0.9$ jet subject to perturbations from the plasma actuator model set to five different operation conditions.

to the plasma actuators at five temperatures ranging from 100 to $2000{ }^{\circ} \mathrm{C}$ which where chosen only as a means to vary the strength of the pressure wave generated and not based on the experimental plasma temperature measurements. Interestingly, each increase in actuator power (temperature and pressure) yields a diminished jet response. In fact, the highest actuator powers run, based on 1000 and $2000{ }^{\circ} \mathrm{C}$ respectively, showed nearly the same jet response. This should not be unexpected because, although the actuator continues to add energy to a mode (in this case the axisymmetric mode), that mode can only support a finite amount of energy. Therefore, if there is enough power to cause the mode to saturate, additional actuator power cannot further amplify the jet response. Also, the initial growth rate becomes steeper and the saturation point moves slightly upstream as the actuator power increases but, like the peak amplitude, only to a limited extent. Unfortunately, one limitation of the LAFPA hardware is the inability to change the input power level and so no data exists to determine exactly what power is required to maximize the jet response. A potential limitation of the actuator model also arises from this data. If the jet response to the actuator model saturates before it reaches the amplitude of the measured response, then it may not be possible to adjust the actuator power so that the simulated jet response matches the measured jet response.

The initial reason for developing the plasma actuator model was to determine the scalability of the LAFPA system. Experiments measuring the jet response to the flapping mode $(\mathrm{m}= \pm 1)$ for both small- and large-scale jets demonstrated the power of the actuators but also showed the need for additional actuators for larger jets. The axisymmetric two-dimensional model cannot support the $\mathrm{m}= \pm 1$ mode, but a preliminary examination of the actuator scalability can be done using the axisymmetric mode $(\mathrm{m}=0)$. Additionally, the nature of the axisymmetric model effectively allows the number of actuators to increase linearly with the jet diameter, testing the scaling theory that the number of actuators required will increase with jet diameter rather than jet area $\left(\right.$ or $\left.\mathrm{D}_{\mathrm{j}}{ }^{2}\right)$. Figure 9 shows the axial development of the axisymmetric mode at the $\mathrm{St}_{\mathrm{DF}}=0.3$ excitation frequency from the $D_{j}=1.0 \mathrm{in}$. OSU jet and the $D_{j}=7.55 \mathrm{in}$. NASA jet. At their respective peak amplitudes, the $D_{j}=1.0 \mathrm{in}$. jet is only about $3 \mathrm{~dB}$ above the $\mathrm{D}_{j}=7.55 \mathrm{in}$. jet. This result gives some hope that the number of actuators required may scale at some value close to the jet diameter which would be much easier and more cost effective than if the required actuators increase with 


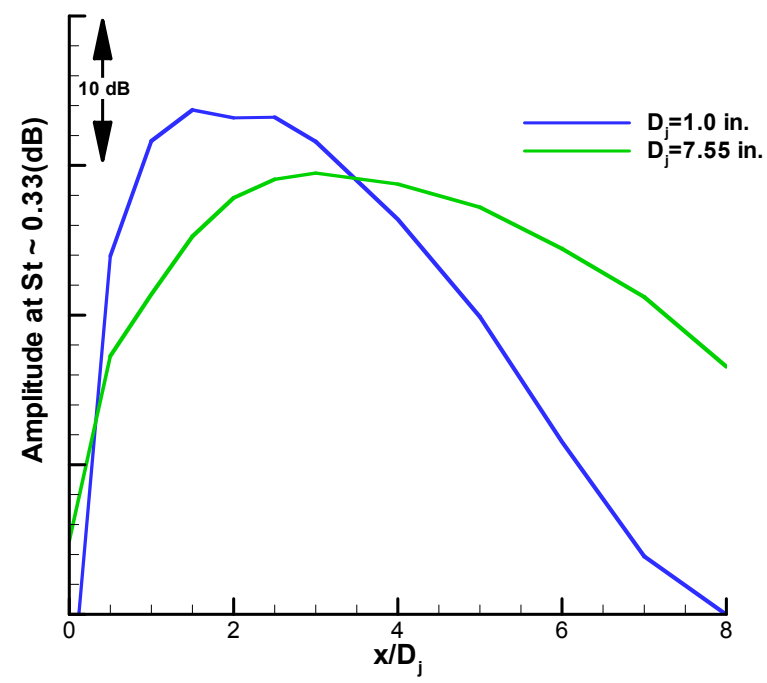

Figure 9.-Axial growth and decay of the jet response at the excitation frequency $\left(\mathrm{St}_{\mathrm{DF}}=0.3\right)$ from a $D_{j}=1.0 \mathrm{in}$. jet and from a $D_{j}=7.55 \mathrm{in}$. jet operating at a $\mathrm{M}_{\mathrm{a}}=0.9$, cold jet exit condition.

the jet area. The data in figure 9, however, also shows other differences that arise when the size of the jet increases. First, the smaller jet responds more quickly to the excitation peaking around $\mathrm{x} / \mathrm{D}_{\mathrm{j}}=2.0$ compared to the larger jet, which has its peak amplitude around $\mathrm{x} / \mathrm{D}_{\mathrm{j}}=3.5$. The response at excited frequency in the $\mathrm{D}_{j}=1.0 \mathrm{in}$. jet also decays much faster then the response from the larger $D_{j}=7.55$ in. jet. Similar results, in which the axial growth of the excited mode from the smaller nozzle showed a sharper peak located farther upstream than the response from the larger nozzle, were noted in the data acquired from both nozzles when the flapping mode $(m= \pm 1)$ was excited (fig. 2$)$. More accurate three-dimensional simulations are needed to address these issues as well as the peak response.

\section{Conclusions}

The idea of temporal control of a jet for noise reduction is not new but, historically, the research has been limited to small-scale, low Reynolds number jets primarily because the flow actuators available did not have the power or frequency response to properly excite a larger jet. The LAFPA were developed at OSU as a high amplitude high frequency actuator for jet control capable of exciting high speed jets. Furthermore, this research has shown the potential for noise reduction through excitation using the LAFPA system. Experiments conducted at OSU showed the ability of the plasma actuators to excite a small-scale high speed jet $\left(\mathrm{D}_{\mathrm{j}}=1.0 \mathrm{in}\right.$.),

significantly changing the flow mixing and the noise produced. These results showed such promise that the LAFPA system was tested on the much larger jet rig $\left(D_{j}=7.55\right.$ in. $)$ located at GRC. At NASA, the plasma actuators showed some limited authority over the jet but the jet response did not achieve the same amplitude as the response measured on the smaller jet. The available hardware, however, limited the number of actuators available during the large-scale test and, therefore, it is not surprising that the jet response was reduced. This raised the question of actuator scalability. Could enough actuators be added to the large-scale jet to get the same amplitude response as that measured on the smaller jet? How many actuators would be required? Because it would be cost prohibitive to address these questions with experiments, simulations using computation fluid dynamics (CFD) are being used to find the answers to these questions so 
that the potential noise reduction from jet excitation can be tested in the future on a large-scale high speed jet that would more closely resemble the jets often found in real world applications.

Central to the study of the scalability of the plasma actuators was the development of a model of the plasma actuator that could be implemented into a CFD solver. There are three forces that could be at work in the plasma system: electohydrodynamic forces, magnetohydrodynamic forces, and Joule heating. Of these forces, recent research has indicated that the Joule heating force is the most likely to impact the type of high-speed flows present in a jet of practical interest. The rapid Joule heating that occurs in the actuator creates a pressure wave that interacts with the flow generating the perturbation for the jet to lock onto. Emission spectroscopy measurements conducted at OSU also showed that the actuator model would have to simulate a very rapid heating, on the order of $20 \mu \mathrm{s}$, up to temperatures of $2000{ }^{\circ} \mathrm{C}$. The model would also have to generate a pressure wave corresponding to this sharp rise in temperature.

A model of the LAFPA was developed for CFD that uses the geometry of the actuator nozzle, particularly the small groove near the nozzle exit that hold the electrodes, to hold a block of cells that would have the working variables (temperature and pressure) periodically reset to simulate the actuator spark. The actuator power would be defined using temperature because some measurements of the temperature have been made. Pressure would then be determined using the temperature and the ideal gas law. This is the major assumption present in the model as the plasma probably does not obey this law but a pressure is needed and the ideal gas law at least gives a consistent method for linking the variables. The actuator power can be calibrated later using three-dimensional simulations to better match the available data.

With the plasma actuator model defined, the Wind-US Unsteady Reynolds Averaged NavierStokes CFD code was used to determine the jet response to the actuator. To implement the model in Wind-US, the jet flow field was first computed with the actuators disabled. Once the baseline jet was computed, the cells in the actuator zone were reset to the actuator temperature and pressure and Wind-US was run for a preset number of iterations corresponding to a periodic cycle time. When complete, Wind-US stopped, the temperature and pressure in the actuator cells were reset, and another cycle started. Data analysis showed that the solution reached a periodic state at a given axial location after four cycles passed that point.

The model and its implementation have been explored using a series of two-dimensional axisymmetric jet simulations. The axisymmetric simulations form one continuous actuator around the complete circumference of the nozzle. Although this is quite different from the eight discrete actuators tested at OSU a comparison of the axial mode growth and decay showed good results. The initial growth rate, the most important aspect for studying actuator scalability, of the axisymmetric mode $(\mathrm{m}=0)$ at the excitation frequency $\left(\mathrm{St}_{\mathrm{DF}}=0.3\right)$ from the actuator model was similar to the over the first jet diameter. The peak response in the simulation data was reduced and farther upstream than measured in the experiment while the decay rate, if not the actual values, was similar in both cases. Overall this is fairly good agreement given that the simulation used an axisymmetric actuator approximation compared to the discrete actuators used in the experiments and the actuator power has not been adjusted beyond the initial assumption that the actuator pressure will relate to the temperature by the ideal gas law. This comparison between the experimental and simulation data show that the actuator model has enough promise to continue development and progress toward more accurate three-dimensional simulations.

Once it was determined by a comparison to available data that the development of this actuator model would continue, additional simulations were run to learn more about the model before applying it to the much more computationally expensive three-dimensional configurations. First, axisymmetric simulations were run to study the adjustability of the LAFPA model and determined that the jet response saturates for actuator temperatures above approximately $1000{ }^{\circ} \mathrm{C}$. Axisymmetric simulations were then run on the $D_{j}=1.0$ in. nozzle and the $D_{j}=7.55$ in. nozzle to examine how the actuators might work as nozzle size changes. These data showed similar 
response amplitudes giving a preliminary indication that the actuators system may scale at a factor close to the jet diameter.

Historically, jet excitation for noise reduction has been explored and has almost always resulted in an increase in noise rather than reduction. However, developments in the diagnostic and simulation tools not previously available may finally allow excitation to be optimized for noise reduction. Experimentally, this will require jet actuators with the power and frequency response to exert control authority over large-scale, high speed jets that are more like the real world jets of practical interest than the small-scale low speed laboratory jets studied in the past. The LAFPA may be the actuator system that can excite these larger jets but scalability of the system has not yet been fully answered. Results based on simplified axisymmetric simulations show promise that the system will scale in a reasonable. Therefore, future work will focus confirming these preliminary by further developing the actuator model and extending it full threedimensional simulations that would incorporate discrete actuators to make better more accurate predictions.

\section{References}

1. Wiltse, J. and Glezer, A., "Manipulation of free shear flows using piezoelectric actuators," J. Fluid Mech. 249, 261-285, 1993.

2. Glezer, A. and Amitay, M., "Synthetic Jets," Ann. Rev. of Fluid Mech. 2002, 503-529, 2002.

3. Raman, G., Hailye, M., Rice, J., "The Flip Flop Nozzle Extended to Supersonic Flows," AIAA Paper 92-2724, 1992.

4. Samimy, M., Adamovich, I., Webb, B., Kastner, J., Hileman, J., Keshav, S., and Palm, P., "Development and characterization of plasma actuators for high-speed jet control," Experiments in Fluids, 37, pp. 577-588, 2004.

5. Samimy, M., Kim, J.-H., Kastner, J., Adamovich, I., and Utkin, Y., "Active control of highspeed and high-Reynolds-number jets using plasma actuators," J. Fluid Mech., 578, 305-330, 2007.

6. Samimy, M., Kim, J.-H., Kastner, J., Adamovich, I., and Utkin, Y., “Active Control of a Mach 0.9 Jet for Noise Mitigation Using Plasma Actuators," AIAA J., 45(4), 890-901, 2007.

7. Samimy, M., Kastner, J., Kim, J.-H., Utkin, Y., Adamovich, I., and Brown, C., "Flow and Noise Control in High Speed and High Reynolds Number Jets Using Plasma Actuators," AIAA Paper 2006-2846, 3rd AIAA Flow Control Conference, 5-8 June 2006.

8. Utkin, Y., Keshav, S., Kim, J.-H., Kastner, J., Adamovich, I., and Samimy, M., "Development and Use of Localized Arc Filament Plasma Actuators for High-speed Flow Control," J. of Physics D: Applied Physics, 40, 685-694, 2007.

9. Leonov, S., Bityurin, V., Savelkin, K., and Yarantsev, D., "Effect of Electrical Discharge on Separation Processes and Shock Position in Supersonic Airflow," AIAA-2002-0355, 40th AIAA Aerospace Sciences Meeting and Exhibit, 14-17 January 2002, Reno, NV.

10. Leonov, S., Bityurin, V., and Yarantsev, D., "The Effect of Plasma Induced Separation," AIAA Paper 2003-3853, 34th AIAA Plasmadynamics and Lasers Conference, 23-26 June 2003, Orlando, FL.

11. Bush, R. Power, G., and Towne, C., "WIND: The Production Flow Solver of the NPARC Alliance," AIAA Paper 98-0935, 1998.

12. Nelson, C.C. and Power, G.D., "CHSSI Project CFD-7: The NPARC Alliance Flow Simulation System," AIAA Paper 2001-0594, 2001.

13. The Wind User's Guide, User Manual, The NPARC Alliance, http://www.grc.nasa.gov/WWW/winddocs/user/index.html.

14. Menter, F.R., "Two-Equation Eddy Viscosity Turbulence Models for Engineering Applications," AIAA Journal, vol. 32, no. 8, pp. 1598-1605, 1994. 
15. Georgiadis, N. and Papamoschou, D., "Computational Investigations of High-Speed DualStream Jets," AIAA Paper 2003-3311, 2003.

16. Georgiadis, N.J., Rumsey, C.L., Yoder, D.A., and Zaman, K.B.M.Q., "Effects of RANS Turbulence Modeling on Calculation of Lobed Nozzle Flowfields," AIAA Paper 2003-1271, 2003.

17. MacCormack, R.W., "Considerations for Fast Navier-Stokes Solvers," presented at the conference on Advances of Flow Simulation Techniques, Davis, CA, May 1997. 


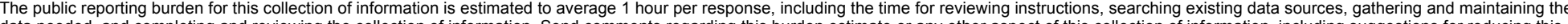

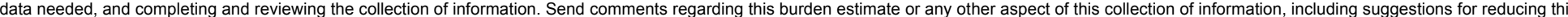

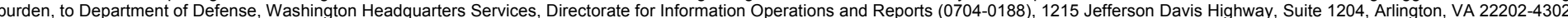

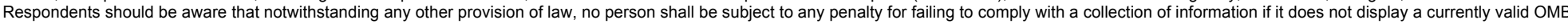
control number.

COntrol number.
1. REPORT DATE (DD-MM-YYYY)
2. REPORT TYPE
3. DATES COVERED (From - To)

01-07-2008

Technical Memorandum

\section{TITLE AND SUBTITLE}

Scalability of Localized Arc Filament Plasma Actuators

5a. CONTRACT NUMBER

5b. GRANT NUMBER

5c. PROGRAM ELEMENT NUMBER

6. AUTHOR(S)

Brown, Clifford, A.

\section{5d. PROJECT NUMBER}

5e. TASK NUMBER

5f. WORK UNIT NUMBER

WBS 984754.02.07.03.17.03

8. PERFORMING ORGANIZATION REPORT NUMBER

E-16539

National Aeronautics and Space Administration

John H. Glenn Research Center at Lewis Field

Cleveland, Ohio 44135-3191

9. SPONSORING/MONITORING AGENCY NAME(S) AND ADDRESS(ES)

National Aeronautics and Space Administration

Washington, DC 20546-0001

10. SPONSORING/MONITORS
ACRONYM(S)
NASA; AIAA
11. SPONSORING/MONITORING
REPORT NUMBER
NASA/TM-2008-215278; AIAA-2008-
3043

\section{DISTRIBUTION/AVAILABILITY STATEMENT}

Unclassified-Unlimited

Subject Category: 71

Available electronically at http://gltrs.grc.nasa.gov

This publication is available from the NASA Center for AeroSpace Information, 301-621-0390

\section{SUPPLEMENTARY NOTES}

\section{ABSTRACT}

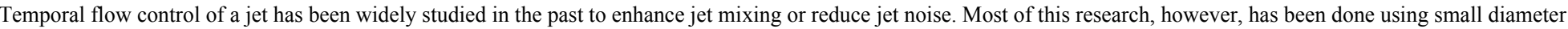

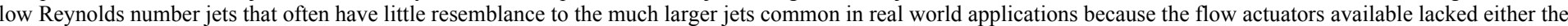

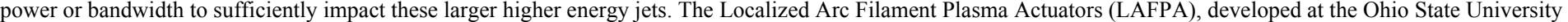

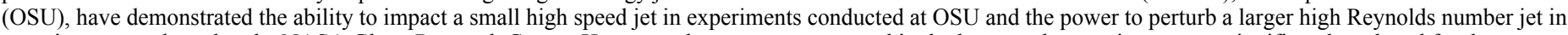

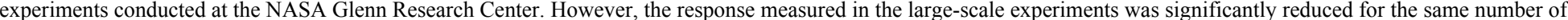

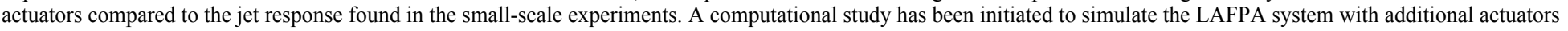

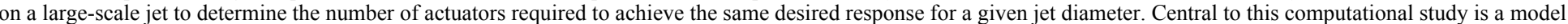

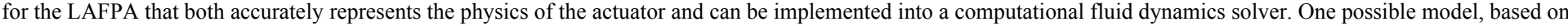

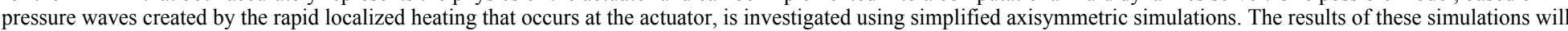

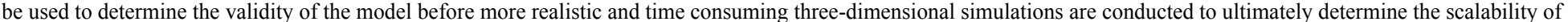
the LAFPA system.

\section{SUBJECT TERMS}

Aerodynamic noise

\begin{tabular}{|l|l|l|l|}
\hline \multicolumn{2}{|l|}{$\begin{array}{l}\text { 16. SECURITY CLASSIFICATION OF: } \\
\begin{array}{l}\text { a. REPORT } \\
\text { U }\end{array}\end{array}$} & $\begin{array}{l}\text { b. ABSTRACT } \\
\text { UIMITATION OF } \\
\text { ABSTRACT }\end{array}$ & $\begin{array}{l}\text { c. THIS } \\
\text { PAGE } \\
\text { U }\end{array}$ \\
\hline
\end{tabular}

18. NUMBER
OF
PAGES
20

19a. NAME OF RESPONSIBLE PERSON

STI Help Desk (email:help@sti.nasa.gov)

19b. TELEPHONE NUMBER (include area code) 301-621-0390 

